\title{
Localization of Caspr2 in Myelinated Nerves Depends on Axon-Glia Interactions and the Generation of Barriers along the Axon
}

\author{
Sebastian Poliak, ${ }^{1}$ Leora Gollan,, ${ }^{1}$ Daniela Salomon, ${ }^{1}$ Erik O. Berglund, ${ }^{2}$ Reiko Ohara, ${ }^{3}$ Barbara Ranscht, ${ }^{2}$ and \\ Elior Peles ${ }^{1}$ \\ ${ }^{1}$ Department of Molecular Cell Biology, The Weizmann Institute of Science, Rehovot 76100, Israel, 2 The Burnham \\ Institute, Neurobiology Program, La Jolla, California 92037, and 'Department of Human Gene Research at Kazusa DNA \\ Research Institute, Chiba 292-0812, Japan
}

\begin{abstract}
Cell recognition proteins of the contactin-associated protein (Caspr) family demarcate distinct domains along myelinated axons. Caspr is present at the paranodal junction formed between the axon and myelinating glial cells, whereas Caspr2 is localized and associates with $\mathrm{K}^{+}$channels at the adjacent juxtaparanodal region. Here we investigated the distribution of Caspr2 during development of peripheral nerves of normal and galactolipids-deficient [ceramide galactosyl transferase (CGT)-/-] mice. This mutant exhibits paranodal abnormalities, lacking all putative adhesion components of this junction, including Caspr, contactin, and neurofascin 155. In sciatic nerves of this mutant, Caspr2 was not found at the juxtaparanodal region but was concentrated instead at the paranodes with Kv1.2. Similar distribution of Caspr2 was found in the PNS of contactin knock-out mice, which also lack Caspr in their paranodes. During development of wild-type peripheral nerves, Caspr2 and Kv1.2 were initially detected at the paranodes
\end{abstract}

Saltatory conduction depends on the generation of specialized domains along myelinated axons in which different sets of ion channels are present (Arroyo et al., 1999; Peles and Salzer, 2000). At the node of Ranvier, the axonal membrane contains high concentrations of voltage-gated $\mathrm{Na}^{+}$channels that are responsible for the regeneration of the action potential (Waxman and Ritchie, 1993). The juxtaparanodal region is located beneath the compact myelin at both sides of each internodal interval and contains delayed rectifier $\mathrm{K}^{+}$channels of the Shaker family, Kv1.1, Kv1.2, and their Kv $\beta 2$ subunit (Wang et al., 1993; Rhodes et al., 1997; Vabnick and Shrager, 1998; Rasband and Shrager, 2000). These channels colocalize and create a complex with Caspr2, the second member of a growing family of putative cell recognition molecules that demarcate distinct domains along myelinated fibers (Poliak et al., 1999). The juxtaparanodal $\mathrm{K}^{+}$channels and Caspr2 are separated from the $\mathrm{Na}^{+}$channels at the node of Ranvier by the paranodal junction, a specialized septate-like

Received May 30, 2001; revised July 12, 2001; accepted July 18, 2001.

This work was supported by grants from the National Multiple Sclerosis Society (Grant RG-3102), the United States-Israel Science Foundation (BSF), Jerusalem, Israel, and the Minerva Foundation to E.P. and from the National Institutes of Health (NS38397) and the March of Dimes Birth Defects Foundation (FY00-240) to B.R. E.P. is an Incumbent of the Madeleine Haas Russell Career Development Chair. We thank Brian Popko for his generous support in making the CGT $-/$ - mice available to us and Jim Trimmer for his kind supply of antibodies to ion channels.

Correspondence should be addressed to Dr. Elior Peles, Department of Molecular Cell Biology, The Weizmann Institute of Science, Rehovot 76100, Israel. E-mail: peles@weizmann.ac.il.

Copyright (C) 2001 Society for Neuroscience $0270-6474 / 01 / 217568-08 \$ 15.00 / 0$ before relocating to the adjacent juxtaparanodal region. This transition was not observed in CGT mice, where Caspr2 and Kv1.2 remained paranodal. Double labeling for Caspr and Caspr2 demonstrated that these two related proteins occupied mutually excluding domains along the axon and revealed the presence of both paranodal and internodal barrier-like structures that are delineated by Caspr. Finally, we found that the disruption of axon-glia contact in CGT-/- nerves also affects the localization of the cytoskeleton-associated protein $4.1 \mathrm{~B}$ along the axon. Altogether, our results reveal a sequential appearance of members of the Caspr family at different domains along myelinated axons and suggest that the localization of Caspr2 may be controlled by the generation of Casprcontaining barriers along the axon.

Key words: Caspr2; myelin; node of Ranvier; axo-glial junction; Schwann cells; $K^{+}$channels

point of contact that is formed between the axolemma and the paranodal loops of the myelinating cells (Rosenbluth, 1995). The axonal membrane at the paranodes contains a complex of cell adhesion molecules that include Caspr (also known as paranodin) (Einheber et al., 1997; Menegoz et al., 1997; Peles et al., 1997) and the glycosylphosphatidyl inositol-linked cell adhesion molecule contactin (Rios et al., 2000; Boyle et al., 2001). A glial component of the paranodal junction was recently identified as neurofascin 155 (NF155), a spliced isoform of the cell adhesion molecule neurofascin that is specifically found at the glial loops (Tait et al., 2000). A schematic diagram summarizing the proteins found in the various subdomains at the nodal region is presented in Figure 9.

The generation and maintenance of specialized domains in myelinated fibers are controlled by glial contact and intrinsic determinants within the axon (Peles and Salzer, 2000). Although the exact mechanisms involved are not completely understood, such organization may require the presence of barriers along the axon that restrict the diff usion of axonal proteins (Winckler et al., 1999). Such barriers may be present at the paranodal junction. Although structurally distinct, the paranodal junctions were suggested to function similarly to tight junctions by providing a fence that restricts the movement of membrane proteins, thereby confining them to specific domains along the axolemma (Rosenbluth, 1995). The importance of axo-glial contact for the proper generation of axonal domains is further supported by the analysis of mutant mice with defective paranodal junctions. These include 
mice deficient for contactin (Berglund et al., 1999; Boyle et al., 2001) and galactolipids-deficient mice (Dupree et al., 1999). The latter lack the enzyme UDP-galactose/ceramide galactosyl transferase (CGT) and are incapable of synthesizing the two major myelin galactolipids galactocerebroside ( $\mathrm{GalC})$ and sulfatide (Coetzee et al., 1996; Bosio et al., 1998). Both of these paranodal mutants lack the transverse bands that are thought to represent the septate-like junctions in peripheral myelinated nerves and exhibit abnormal localization of Caspr and Kv1.1 along their axons (Bosio et al., 1998; Dupree et al., 1998, 1999; Boyle et al., 2001). To further understand the molecular mechanisms involved in the generation and maintenance of distinct functional domains along myelinated axons, we have investigated the distribution of the Caspr2/Kv1.2 complex during development of peripheral nerves in wild-type and paranodal mutant mice. Our findings suggest that the localization of these proteins depends on the presence of axonal barrier-like structures that are outlined by Caspr at the paranodal junction and along the internodal membrane.

\section{MATERIALS AND METHODS}

Animals and antibodies. Generation and genotyping of CGT and contactin null animals have been described previously (Coetzee et al., 1996; Berglund et al., 1999). Wild-type control animals were derived from the same litters. Antibodies to Casprs include polyclonal antibodies P6061 and $\mathrm{P} 4344$ directed to the intracellular region of Caspr or Caspr2, respectively, as well as monoclonal antibody M275, which is directed to the extracellular domain of Caspr (Peles et al., 1997; Poliak et al., 1999). Monoclonal antibodies against $\mathrm{Na}^{+}$channels and Kv1.2 (Bekele-Arcuri et al., 1996; Rasband et al., 1999), as well as polyclonal antibodies against contactin (Berglund et al., 1999), were described previously. NF155specific antibodies were generated by immunizing rabbits with a mixture of two peptides, IRVLNSTAISLQWNRVYPD and RQQASFPGDRPRGV VGRLF (amino acid positions 822-840 and 869-887, respectively), derived from the third FNIII repeat of rat neurofascin (Davis et al., 1996).

Immunoprecipitation and immunoblot analysis. Coimmunoprecipitation experiments were done using brain membranes prepared from wild-type or CGT $-/-$ animals. Brains from four mice were pooled and homogenized in a buffer containing $20 \mathrm{~mm}$ HEPES, pH 7.4, $0.32 \mathrm{M}$ sucrose, $1 \mathrm{~mm}$ EGTA, $1.5 \mathrm{~mm} \mathrm{MgSO}_{4}, 10 \mu \mathrm{g} / \mathrm{ml}$ aprotinin and leupeptin, and $1 \mathrm{~mm}$ phenylmethyl-sulfonyl fluoride (PMSF). Nuclei and heavy cell debris were removed by low-speed centrifugation $(1000 \times g)$ for $10 \mathrm{~min}$, and the supernatant was subjected to high-speed centrifugation $(40,000 \times g)$ for $60 \mathrm{~min}$. Membrane solubilization, immunoprecipitation, and immunoblots were conducted as described previously (Poliak et al., 1999).

Immunofluorescence. Sciatic nerves were dissected and immersed in Zamboni's fixative for $10 \mathrm{~min}$. In some cases, nerves were first fixed in $4 \%$ paraformaldehyde and teased before immersion in Zamboni's fixative. After desheathing, nerves were teased on gelatin-coated slides, dried for $2 \mathrm{hr}$, and frozen at $-20^{\circ} \mathrm{C}$. Preparation and staining of optic nerve sections have been described previously (Poliak et al., 1999). The preparations were post-fixed/permeabilized in methanol at $-20^{\circ} \mathrm{C}$ for 20 min or permeabilized in $\mathrm{PBS} / 0.5 \%$ Triton X-100 for $10 \mathrm{~min}$ for optimal staining of 4.1B. Slides were washed and blocked for 30 min with PBS containing $10 \%$ normal goat serum, $0.1 \%$ Triton $\mathrm{X}-100$, and $1 \%$ glycine. The samples were incubated overnight at $4^{\circ} \mathrm{C}$ with the different primary antibodies described above diluted in blocking solution. Slides were washed three times for $5 \mathrm{~min}$ in PBS and incubated for $1 \mathrm{hr}$ in secondary antibodies: anti mouse-Cy3 or biotinylated anti-rabbit (Jackson ImmunoResearch, West Grove, PA). The latter was washed in PBS and reacted with streptavidin-Alexa-488 (Molecular Probes, Eugene, OR) for $45 \mathrm{~min}$ and was further processed as described previously (Poliak et al., 1999). Immunofluorescence was viewed and analyzed using a Deltavision widefield deconvolution microscope (Applied Precision), using a Bio-Rad confocal microscope (Bio-Rad, Richmond, CA) or a Zeiss Axioplan microscope equipped with SPOT-II (Diagnostic Instruments) cooled CCD camera.

\section{RESULTS}

\section{Paranodal junction components in CGT and contactin mutants}

Previous work showed that Caspr is either absent or only weakly present in the paranodes of galactolipids mutant mice (Dupree et al., 1999). It was suggested that the paranodal defects observed in this mutant result from inappropriate targeting of a glial adhesion component to the paranodal loops (Dupree et al., 1999; Popko, 2000). To further characterize this mutant, we examined the distribution of contactin and NF155, two adhesion molecules that are found at the neuronal and glial sides, respectively, of the paranodal junction (Rios et al., 2000; Tait et al., 2000). Although in wild-type animals NF155 and contactin show a similar distribution to Caspr at the paranodes and the mesaxon, in CGT-/mice these adhesion molecules were hardly detected in the paranodal region (Fig. 1). As observed in wild-type nerves (Tait et al., 2000), NF155 was still detected in the Schmidt-Lanterman incisures (data not shown), indicating that it was specifically mislocalized at the paranodes and the mesaxon. Similarly, NF155 staining was markedly reduced in the paranodes of contactin mutant mice, which also exhibit disruption of the paranodal septate-like junction (Fig. 1) (Boyle et al., 2001). In both paranodal mutants, some residual NF155 staining could be detected occasionally in the paranodal loops, but it was clearly distinct from the wild-type nerve and did not appear to be concentrated at the paranodal junction. These observations indicate that localization of the different adhesion components at the paranodal junction is interdependent, suggesting that galactolipids may affect the local differentiation of myelinated axons by regulating the proper localization of NF155 to the glial loops.

\section{Distribution of Caspr2 in CGT knock-out mice}

The close association between Caspr 2 and $\mathrm{K}^{+}$channels raises the question of whether these proteins are still colocalized in myelinated nerves of CGT $-/-$ and contactin null mice, which display abnormal localization of $\mathrm{K}^{+}$channels along their axons (Dupree et al., 1999; Boyle et al., 2001). In the sciatic nerves from these mutants, Caspr2 was found adjacent to the nodes of Ranvier, which were labeled with a $\mathrm{Na}^{+}$channel antibody (Fig. 2). Similar paranodal localization was found for $\mathrm{K}^{+}$channels subunits Kv1.2 (Fig. 1) and Kv1.1 (data not shown) (Dupree et al., 1999; Boyle et al., 2001). Although in wild-type animals Caspr 2 and $\mathrm{K}^{+}$channels were present at $93 \%$ of the juxtaparanodes, they were localized at the paranodes in 94 and $96 \%$ of the sites in CGT and contactin mutant nerves, respectively. In the remaining $4-6 \%$ of the cases, these molecules were not at all or only weakly detected along the axon. Double labeling for Caspr2 and Kv1.2 demonstrated that these proteins were colocalized at all of the sites examined. In CGT and contactin mutant mice, Caspr2 and $\mathrm{K}^{+}$ channels did not occupy the entire paranodal length but were more concentrated near the nodes. This labeling pattern was clearly distinct from the distribution of Caspr in wild-type animals. Altogether, these experiments demonstrate that Caspr2 is aberrantly relocated with $\mathrm{K}^{+}$channels to the paranodes in two different mutant mice that exhibit paranodal junction defects. Thus, the presence of the Caspr/contactin complex in the paranodes may restrict the movement of Caspr $2 / \mathrm{K}^{+}$channels toward the nodes.

We have previously described that, in the CNS, Caspr2 colocalizes and forms a complex with Kv1.2, Kv1.1, and their Kv $\beta 2$ subunits (Poliak et al., 1999). Myelinated fibers in the CNS of CGT $-/-$ mice exhibit more severe morphological alterations as 


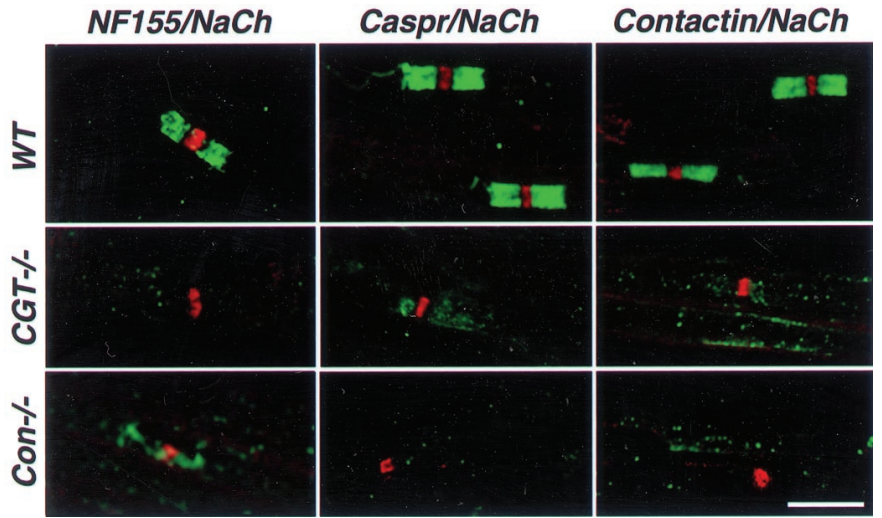

Figure 1. Aberrant localization of paranodal junction proteins in peripheral nerves of CGT and contactin knock-out mice. Teased sciatic nerves were prepared from either 25-d-old wild-type (WT) or CGT $(C G T-/-)$ mice or from 17-d-old contactin knock-out (Con-/-) animals. The preparations were labeled with a mouse monoclonal antibody to $\mathrm{Na}^{+}$channel ( $\mathrm{NaCh}$, in red) and an antibody to neurofascin 155 (NF155), Caspr, contactin, or Caspr2 (all in green), as indicated at the top of each panel. Scale bar, $10 \mu \mathrm{m}$.

compared with the PNS (Dupree et al., 1998; Popko, 2000). Analyses of optic nerves of wild-type and CGT-/- mice revealed that, in contrast to the PNS, Caspr 2 was found only infrequently at the juxtaparanodes, and in most fibers was either not detected or diffused along the axon (Fig. $3 A$ ). A similar distribution was revealed using an antibody to Kv1.2. To determine whether Caspr 2 and $\mathrm{K}^{+}$channels associate in CGT-/- mice, brain membrane lysates from both wild-type and mutant animals were subjected to immunoprecipitation with anti-Kv1.2 or Kv2.1 antibodies followed by immunoblotting with an antibody to Caspr2. As depicted in Figure 3B, Caspr2 could be coimmunoprecipitated from CGT $-/-$ mutant brains with an antibody against the Kv1.2 but not with an antibody to the control Kv2.1 subunit. These experiments demonstrate that although Caspr2 and Kv1.2 are found in abnormal positions along the axon in the CNS of

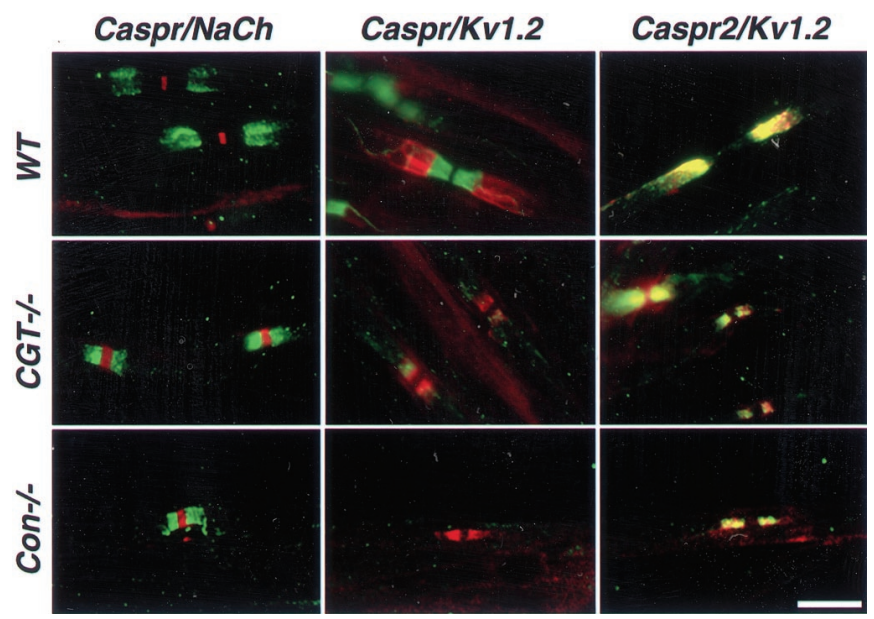

Figure 2. Distribution of $\mathrm{K}^{+}$channels and members of the Caspr family in peripheral nerves of wild-type and paranodal mutant mice. Teased sciatic nerve preparations from wild-type $(W T)$ or CGT $(C G T-/-)$ or contactin null mice (Con-/-) were labeled with different combination of antibodies as indicated at the top of each panel. Caspr and Caspr2 labeling is shown in green, whereas that of $\mathrm{Na}^{+}(\mathrm{NaCh})$ and $\mathrm{K}^{+}$channels $(K v 1.2)$ is shown in red. Scale bar, $10 \mu \mathrm{m}$.

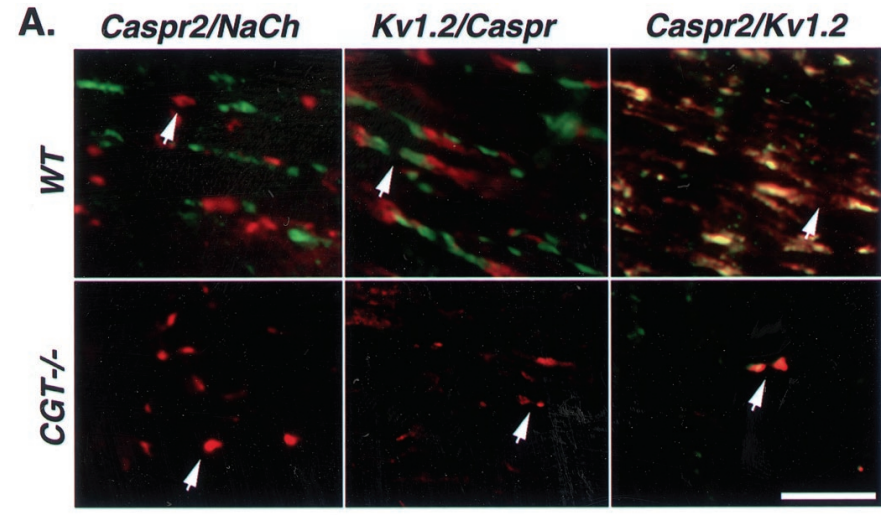

B.

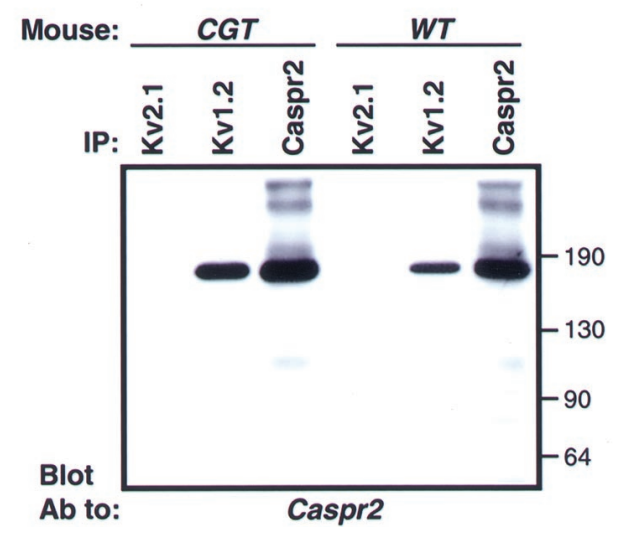

Figure 3. Caspr $2 / \mathrm{K}^{+}$channels complex is mislocalized in the CNS of CGT knock-out mice. $A$, Longitudinal sections of optic nerves derived from 45-d-old wild-type (WT) or CGT $(C G T-/-)$ mice were labeled with the different combination of antibodies as indicated at the top of each panel. Caspr and $\mathrm{K}^{+}$channels $(K v 1.2)$ are labeled in green, and Caspr2 and $\mathrm{Na}^{+}$channels $(\mathrm{NaCh})$ are labeled in red. The location of a node is marked by an arrow. Scale bar, $20 \mu \mathrm{m}$. B, Association of Caspr2 with $\mathrm{K}^{+}$ channels. Solubilized brain membranes from wild-type $(W T)$ or CGT knock-out animals $(C G T)$ were subjected to immunoprecipitation with specific antibodies to either the Kv1.2 or Kv2.1 subunits of $\mathrm{K}^{+}$channels, or to Caspr2 as indicated $(I P)$. Note that from one brain that was used for each set of immunoprecipitations, $40 \%$ of the lysate was used for Kv1.2 and Kv2.1 antibodies, whereas $20 \%$ was used for Caspr2. The complexes were separated on SDS-gel and immunoblotted with an antibody to Caspr2. The location of molecular weight markers is shown on the right in kilodaltons.

CGT $-/-$ mice, they are still associated in a physical complex as they are in wild-type animals.

\section{Caspr2/ $\mathrm{K}^{+}$channel complex during development}

The findings that Caspr 2 and $\mathrm{K}^{+}$channels are colocalized together in wild-type as well as in two paranodal mutant mice raise the question of whether the association between these molecules is important for their correct distribution along the nerve during development. In the rat sciatic nerve, $\mathrm{K}^{+}$channels are first detected at the nodes and paranodes and later in the juxtaparanodal region (Vabnick et al., 1999). Analyses of the distribution of Caspr2 and Kv1.2 in sciatic nerves of wild-type mice showed that both proteins could be detected from postnatal day 8 onward in the juxtaparanodal region and to a lesser extent in the paranodes (Fig. 4). At this age, $\mathrm{Na}^{+}$channels were found at all nodes, with Caspr already occupying the entire paranode. Caspr 2 and $\mathrm{K}^{+}$channel clustering was frequently observed in a ring-like shape in the paranodal/juxtaparanodal border, often in an asymmetric manner (Fig. 4 and data not shown). In contrast, in sciatic 


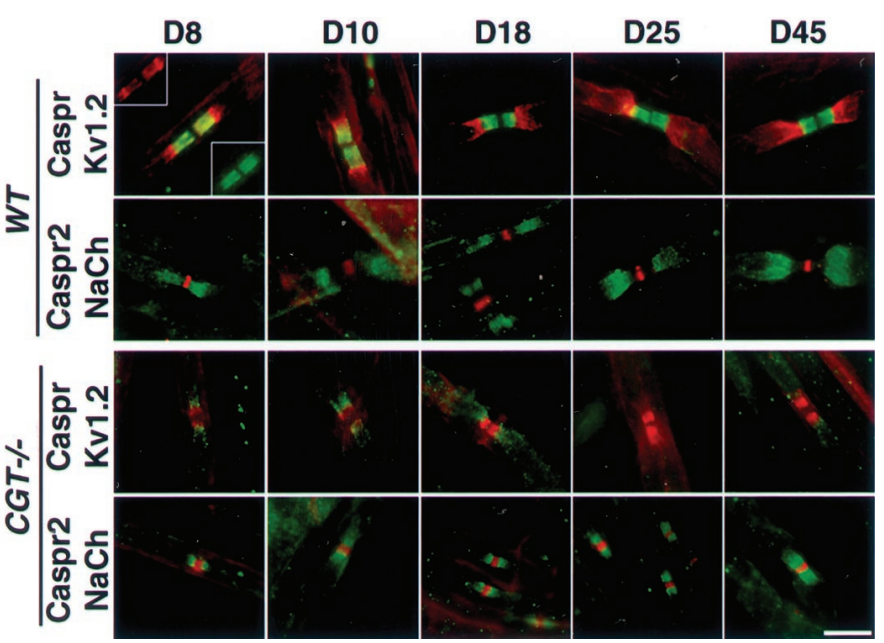

Figure 4. Distribution of Caspr proteins and ion channels during PNS development. Teased sciatic nerves from wild-type $(W T)$ and CGT mutant mice $(C G T-/-)$ were prepared at different days during development as indicated on the top. Double staining was performed using Caspr ( green) and Kv1.2 (red) or Caspr2 (green) and $\mathrm{Na}^{+}$channel (NaCh, red) antibodies as indicated on the left of each row. Insets in the first panel show labeling for either Caspr (bottom inset) or Kv1.2 (top inset). Note that at day $8, \mathrm{~K}^{+}$channels are found in both paranodes and juxtaparanodal regions. In the CGT mice, Caspr 2 and $\mathrm{K}^{+}$channels remain in the paranodes at all ages. Scale bar, $10 \mu \mathrm{m}$.

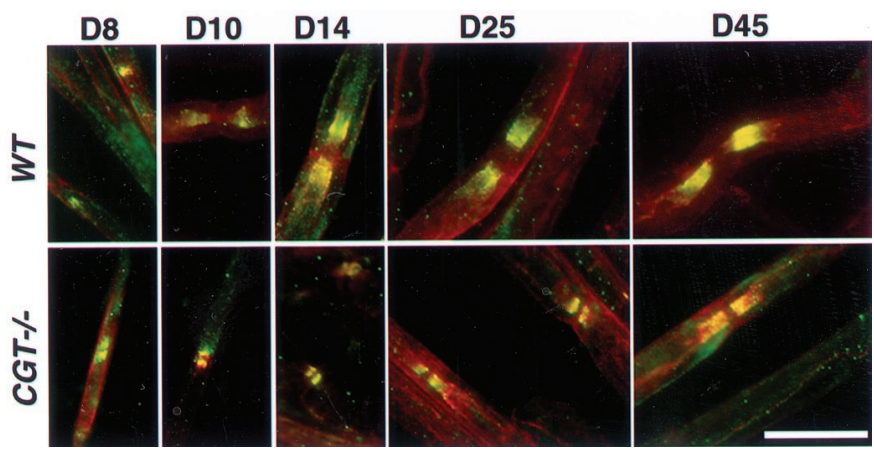

Figure 5. Caspr2 and $\mathrm{K}^{+}$channels appear together in axonal domains during development. Merged images of double staining for Caspr2 ( green) and Kv1.2 (red) performed on teased sciatic nerves from wild-type $(W T)$ and CGT mutant mice $(C G T-/-)$ at different days during development as indicated on the top. The left top panel shows the coappearance of Caspr2 and Kv1.2 in heminodes. Scale bar, $10 \mu \mathrm{m}$.

nerves from $\mathrm{CGT}-/-$ mice, Caspr 2 and $\mathrm{K}^{+}$channels were detected in the paranodes at all ages examined. Doubleimmunofluorescence labeling for Caspr2 and Kv1.2 showed that these proteins appear together during development of the wildtype as well as CGT-/- nerves (Fig. 5). These results demonstrate that Caspr2 and $\mathrm{K}^{+}$channels emerge as a complex during the development of the nerve at the paranode/juxtaparanodal border, which then moves from the paranodes to the juxtaparanodal region. In CGT-/- fibers, where Caspr and contactin are not in place, the paranodal domain is not defined, and the Caspr $2 / \mathrm{K}^{+}$channel complex remains localized adjacent to the nodes.

\section{Caspr family members occupy mutually excluding domains along the axons}

The reduced paranodal accumulation of Caspr in sciatic nerves of CGT-/- mice (Dupree et al., 1999; this work), along with the

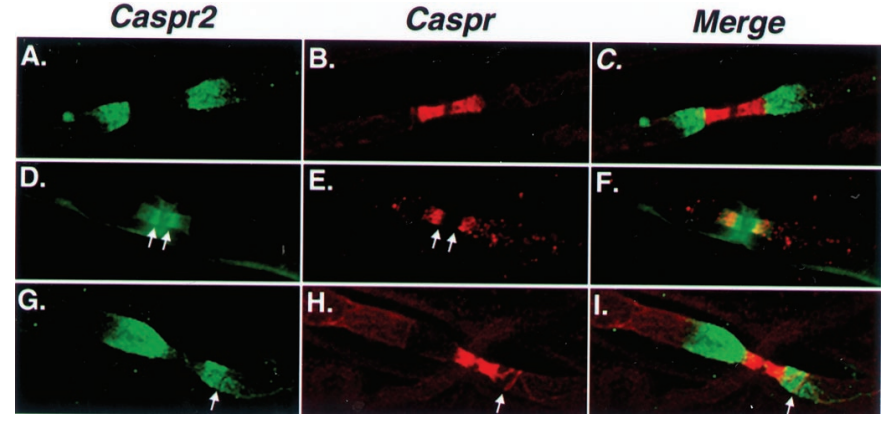

Figure 6. Caspr and Caspr $2 / \mathrm{K}+$ complex occupy mutually excluding domains along the axon. Wild-type $(A-C$ and $G-I)$ or CGT-/- $(D-F)$ nerves were labeled for Caspr (red; $B, E, H$,$) and Caspr2 (red; A, D, G)$ as indicated. The merged images of each experiment are shown on the right panels. In CGT $-/-$ nerve, high levels of Caspr2 are detected in regions that lack Caspr $(D, E$, double arrows). Similarly, in wild-type animals, a line of Caspr staining in the juxtaparanodes does not overlap with Caspr2 $(G-I$, single arrow $)$. Note that the weak labeling of the outer aspects of the myelin sheath $(D)$ is not specific and does not reflect Caspr staining in Schwann cells.

relocation of Caspr $2 / \mathrm{K}^{+}$channels to the paranodes, enables us to assess whether Caspr family members could coexist along the same axonal domains. To this end, we immunolabeled sciatic nerves for Caspr and Caspr2 or Kv1.2 and analyzed those sites in which some paranodal accumulation of Caspr was still detected. In contrast to wild-type nerves that show a clear and sharp border between the paranodes and the juxtaparanodal region (Fig. 6C), in CGT $-/-$ mutant nerves we observed a gradient of Caspr2 expression, with the highest concentration proximal to the node (Fig. 6D-F). At these sites, Caspr accumulated but did not overlap with the area that displayed the highest level of Caspr2 expression. This pattern of Caspr 2 or $\mathrm{K}^{+}$channel distribution was detected in all of the sites that also showed partial paranodal accumulation of Caspr in the adult nerve. In addition to its localization at the paranodes, in wild-type nerves Caspr was also found as a thin line bordered by parallel lines of $\mathrm{K}^{+}$channels and Caspr 2 along the internodes and just below the Schmidt-Lanterman incisures (Fig. 6) (Arroyo et al., 1999, 2001). Passing through the juxtaparanodal region, this line of Caspr staining appears as a groove that was devoid of Caspr2 or $\mathrm{K}^{+}$channels (Fig. $6 G-L$ ), demonstrating that even when present at the same domain, $\mathrm{Caspr}$ and the Caspr $2 / \mathrm{K}^{+}$complex are still separated.

In axons of adult wild-type mice, rings of Caspr were detected repeatedly along the internodes and at the ends of the juxtaparanodal region (Fig. 7). Labeling for either Caspr2 or Kv1.2 revealed that these proteins accumulated at one side of the ring. Furthermore, the directionality of this unilateral accumulation seemed to be determined by the proximity to the node: Caspr and the Caspr $2 / \mathrm{K}^{+}$channel complex were always accumulated, keeping the same polarity as that observed in the closest paranode/ juxtaparanodal region. Altogether, these results show that Caspr family members occupy mutually excluding domains along myelinated axons and suggest that the presence of Caspr along the axon at sites other than the paranodal junction may also serve as a barrier for the movement of Caspr 2 and $\mathrm{K}^{+}$channels in the membrane.

\section{Localization of protein 4.1B to the paranodal junction depends on members of the Caspr family}

The unique localization of members of the Caspr family along myelinated axons may require the attachment to the cytoskeleton 


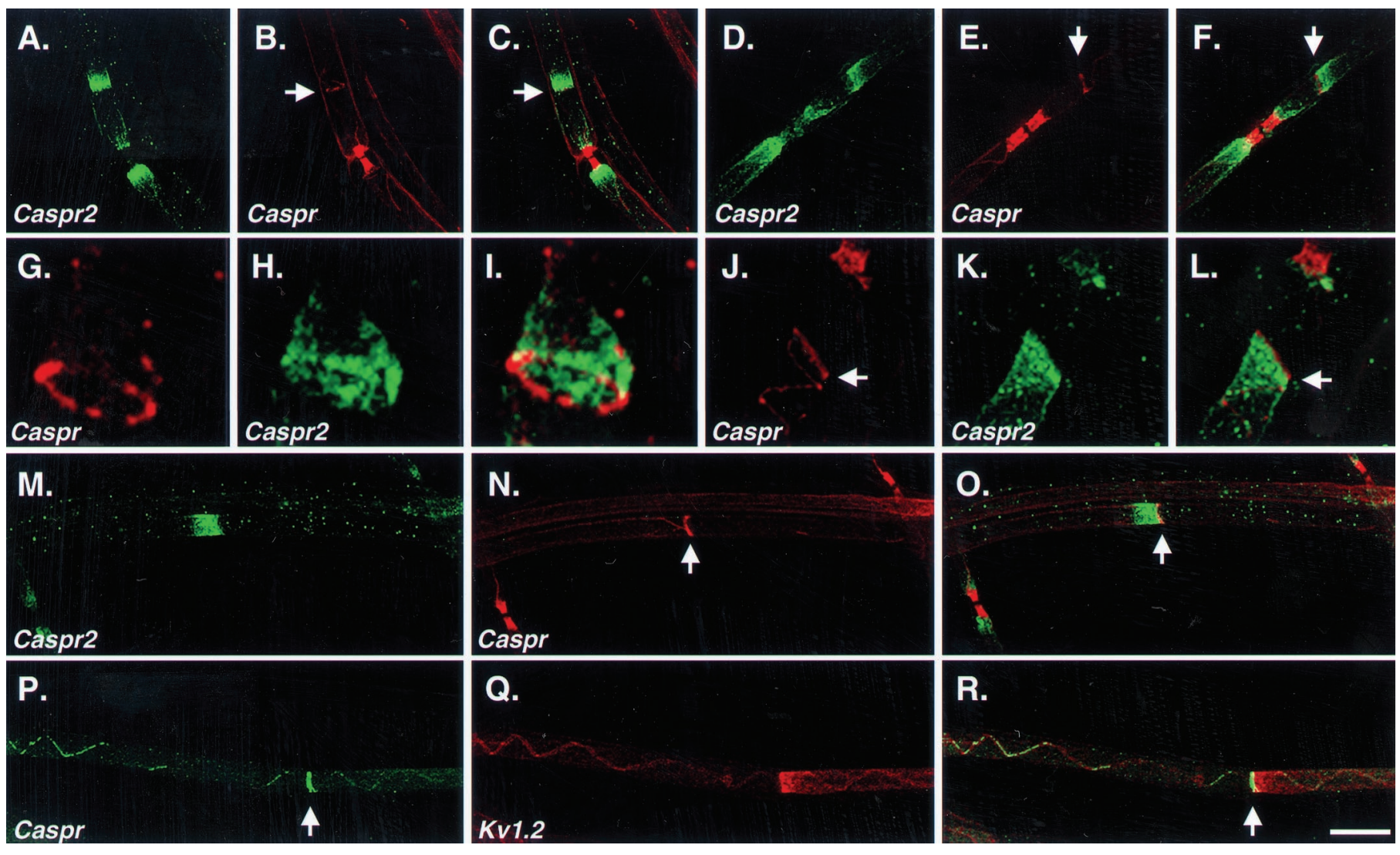

Figure 7. Internodal localization of Caspr and Caspr $2 / \mathrm{K}^{+}$channel complex. Teased fibers of adult mouse sciatic nerves were stained for Caspr (red; $B, E, G, J, N)$ and Caspr2 (green; $A, D, H, K, M)$ or for Caspr (green; $P$ ) and Kv1.2 (red; $Q$ ). Merged images for each set of labeling are also shown $(C, F, I, L, O, R)$. Scale bar, $10 \mu \mathrm{m}$. Note that both Caspr2 and Kv1.2 are restricted to only one side of the Caspr ring, keeping the same polarity as that of the closest paranode.
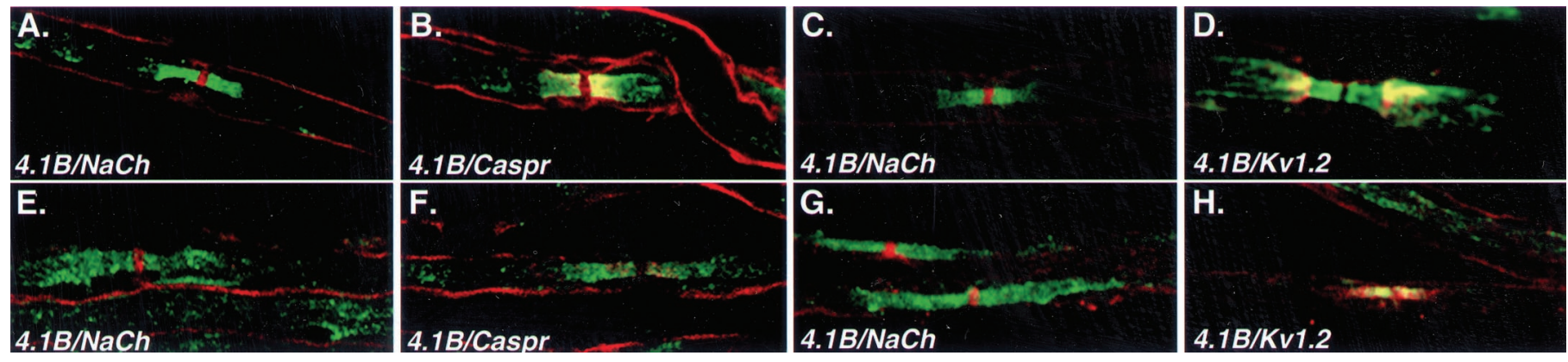

Figure 8. Distribution of protein 4.1B in peripheral nerves of wild-type and paranodal mutant mice. Teased sciatic fibers from day $12(A, B)$ and adult $(C, D)$ wild-type animals, or 12-d-old $(E, F)$ and adult $(G, H)$ CGT-/- mice were double labeled with an antibody to protein 4.1B (green) and an antibody to $\mathrm{Na}^{+}$channel, Kv1.2, or Caspr (all in red) as indicated. Note that in adult CGT $-/-$nerve, paranodal concentration of protein 4.1B depends on the abnormal accumulation of the Caspr2/Kv1.2 complex at these sites.

by binding to members of the protein 4.1 family. Such proteins were shown to bind to the cytoplasmic domain of Caspr (Menegoz et al., 1997), as well as to neurexin IV, the Drosophila homolog of Caspr2 (Baumgartner et al., 1996). This family consists of four distinct proteins (Huang et al., 1993; Walensky et al., 1998, 1999; Yamakawa et al., 1999; Parra et al., 2000), of which only 4.1B was found at the paranodes in the CNS (Ohara et al., 2000) (L. Gollan and E. Peles, unpublished observation). To determine the localization of protein $4.1 \mathrm{~B}$ in the PNS, we first analyzed its distribution in sciatic nerve of wild-type animals at postnatal day 12. At this developmental stage, Caspr was found at all paranodes, whereas Caspr2 was found only in part of the juxtaparanodes. Protein 4.1B was observed at the paranodal junction and was occasionally detected also at the juxtaparanodal region (Fig. 8). The presence of protein $4.1 \mathrm{~B}$ at the juxtaparanodes increased with age and was more prominent in adult nerves, where it was localized with Caspr2 and Kv1.2. In contrast, in sciatic nerve of 12-d-old CGT mice, protein 4.1B was distributed along the axon and weakly detected at the paranodes. When protein $4.1 \mathrm{~B}$ was detected at the paranodes, it was found at sites in which either Caspr or the Caspr2/Kv1.2 complexes were concentrated. This was more conspicuous in adult sciatic nerves. While in wild-type animals protein $4.1 \mathrm{~B}$ was found at the paranodes and the juxtaparanodal region, in CGT $-/-$ nerves it was 
diffused along the axon or detected at the paranodes together with the Caspr2/Kv1.2 complex (Fig. 8). In summary, these results indicate that mislocalization of both Caspr proteins in galactolipids-deficient mice is also accompanied by aberrant distribution of protein 4.1B, suggesting that members of the Caspr family may regulate the localization of $4.1 \mathrm{~B}$ in myelinated axons.

\section{DISCUSSION}

\section{Sequential appearance of Caspr and Caspr2 during development}

We have shown previously that Caspr2 is localized and associates with members of the Shaker $\mathrm{K}^{+}$channels family, Kv1.1, Kv1.2, and their $\operatorname{Kv} \beta 2$ subunit at the juxtaparanodal region (Poliak et al., 1999). This association occurs indirectly and probably involves the interaction of Caspr2 with a PDZ-containing protein (Poliak et al., 1999). In this work, we compared the distribution of Caspr2 and Kv1.2 during development of peripheral nerves of wild-type and mutant mice with paranodal abnormalities. At all ages tested, Caspr2 always colocalized with $\mathrm{K}^{+}$channels. In sciatic nerves of wild-type animals, Caspr 2 could be detected as early as day 8 at the paranodes and the juxtaparanodal region, where it had already been colocalized with Kv1.2. Comparatively, at this age, Caspr was present at all paranodes. As development progressed, Caspr2 translocated to the adjacent juxtaparanodal region until it became completely absent from the paranodes in the adult. This pattern is in agreement with a previous study, demonstrating a role for these paranodal $\mathrm{K}^{+}$channels in preventing repetitive firing during development of peripheral nerves (Vabnick et al., 1999). In contrast to the wild-type nerves, in the galactolipidsdeficient mice, Caspr2 and Kv1.2 were initially detected at the paranodes but did not relocate to the juxtaparanodal region and remained mostly paranodal in the adult (94 and $96 \%$ of the sites, respectively). A similar distribution was reported previously for Kv1.1 in the adult sciatic nerve ( $85 \%$ of the sites examined) (Dupree et al., 1999). Taken together, these results demonstrate that the entire complex, which contains Caspr2 and distinct $\mathrm{K}^{+}$ channel subunits, is abnormally found at the paranodes in this mutant. Furthermore, although in the CNS, Caspr2 and Kv1.2 were less confined to the juxtaparanodal region; they were invariably colocalized to ectopic sites and still generated a stable complex. The transient appearance of Caspr2 and Kv1.2 in the paranodes during development of peripheral nerves raises the possibility that these proteins may be targeted directly to this site. In this regard, the paranodal junction may serve as a sorting center much like the proposed role of tight junctions in epithelial cells (Zimmermann, 1996; Zahraoui et al., 2000).

\section{Caspr and Caspr2 occupy mutually excluding domains in myelinated axons}

During development of wild-type peripheral nerves, Caspr2/ $\mathrm{K}^{+}$ channel complexes are excluded from the paranodes, which are already occupied by Caspr. This observation is further supported by analyses of sciatic nerves of CGT $-/-$ mice. In contrast to wild-type nerves, which exhibit a sharp boundary between Caspr2 and Caspr zones, no such border was detected at sites that still showed paranodal accumulation of Caspr in CGT-/- mutants (Fig. 6). At these sites, Caspr distinctly occupied only the distal part of the paranodal region (i.e., in respect to the nodes) and avoided the more proximal part that contained a high concentration of Caspr2. It should be noted that paranodal accumulation of Caspr is composed of a number of rings that represent each turn of the myelin wrap and thus does not represent a uniform domain
(Arroyo et al., 1999; Pedraza et al., 2001). This, in turn, may allow the $\mathrm{K}^{+}$channels to accumulate as stripes between the Caspr rings at the paranodes. This notion is well supported by ultrastructural data, revealing the presence of distinct rows of particles at the paranodal axolemma that are regularly positioned between the paranodal loops (Rosenbluth, 1995). In addition to its paranodal localization, the Caspr/contactin complex is also present as a thin line at the inner mesaxon and below the Schmidt-Lanterman incisures (Menegoz et al., 1997; Arroyo et al., 1999; Rios et al., 2000). When this line was present at the juxtaparanodes, it was constantly detected in a groove, which was devoid of Caspr2 or Kv1.2. The observation that $\mathrm{Caspr}$ and the Caspr $2 / \mathrm{K}^{+}$channel complex always occupy excluding zones in the PNS is consistent with recent data demonstrating that although in some spinal cord axons $\mathrm{K}^{+}$channels were found at the paranodal region, they did not overlap with Caspr labeling (Rasband and Trimmer, 2001).

\section{Localization of Caspr2 in myelinated axons depends on Caspr-containing domains}

In addition to their proposed role in anchoring the myelin to the axon and in forming a partial barrier that isolates the periaxonal space from the nodes, the paranodal junctions were proposed to physically demarcate boundaries that limit the lateral diff usion of membrane components (Rosenbluth, 1995; Peles and Salzer, 2000). The mislocalization of Kv1.1 (Dupree et al., 1999), Caspr2, $\mathrm{Kv1.2}$, and protein 4.1B in CGT $-/-$ mice described here strongly supports such barrier-like function. Surprisingly, in addition to the paranodes, we observed an accumulation of Caspr2 and $\mathrm{K}^{+}$ channels near rings of Caspr at the end of the juxtaparanodes and along the internodal region, suggesting the existence of such structures also at these domains. In principal, the accumulation of Caspr $2 / \mathrm{K}^{+}$channels at these sites could reflect a stopping of moving complexes at the axonal membrane, or, less likely, an anchorage and sorting site for newly arriving Caspr $2 / \mathrm{K}^{+}$channel complexes. We propose that these rings are similar to those that are squeezed together in the paranodes and most likely represent similar barrier properties as found at the paranodes to restrict the movement of axonal components, including cell adhesion receptors and ion channels. Remarkably, the accumulation of Caspr $2 / \mathrm{K}^{+}$channels near such sites occurred in only one side of the ring and was always directed toward the closest node, indicating that the internodal region itself is polarized.

\section{Molecular mechanisms of paranodal phenotype of galactolipids-deficient mice}

To date, three transmembrane proteins were found to reside at the paranodal junction. These include Caspr (Einheber et al., 1997; Menegoz et al., 1997) and the two immunoglobulin cell adhesion molecules, contactin and NF155 (Rios et al., 2000; Tait et al., 2000). Caspr and contactin form a complex (Peles et al., 1997) that is found at the paranodes (Rios et al., 2000), and both are essential for the generation of the paranodal septate-like junction (Bhat et al., 2001; Boyle et al., 2001). Similarly, galactolipids-deficient mice also exhibit paranodal abnormalities and lack the transverse bands and Caspr in their paranodes (Dupree et al., 1998, 1999). Here, we extended these observations and show that the paranodes of peripheral myelinated nerves of CGT $-/-$ mice are also lacking contactin and NF155. This result demonstrates that disruption of normal axo-glial contact in these mice is accompanied by the disappearance of all known components of the paranodal junction (Fig. 9). Furthermore, disruption of axon-glia contact in CGT mice not only results in mislocal- 


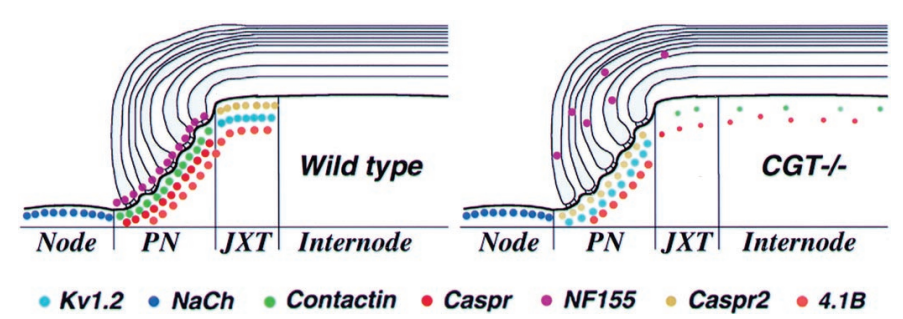

Figure 9. Molecular composition of the nodal region in peripheral nerves. Schematic summary illustrating the distribution of cell adhesion molecules, ion channels, and cytoplasmic proteins along myelinated nerves of wild-type and galactolipids-deficient mice $(C G T-/-)$. The nodal region is divided into several distinct domains, including the node of Ranvier, paranodal $(P N)$, juxtaparanodal $(J X T)$, and internodal regions. In both wild-type and $\mathrm{CGT}-/-$ mutant nerves, $\mathrm{Na}^{+}$channels are present at the nodes of Ranvier. In wild-type animals, Caspr and contactin label the axonal side of the paranodal junction, whereas neurofascin 155 (NF155) is found at the glial loops. Caspr2 and Kv1.2 are present as a complex at the juxtaparanodal area, which is located under the compact myelin. In contrast to the wild-type nerves, in peripheral nerves of the CGT - / - mutant, Caspr, contactin, and neurofascin are no longer present at the paranodal junction. Caspr is primarily distributed along the axon, whereas NF155 is weakly diff used at the paranodal loops area. Disruption of the axo-glial junction results in relocation of Caspr2 and Kv1.2 from the juxtaparanodal region to the adjacent paranode. In wild-type nerves, the cytoplasmic protein $4.1 \mathrm{~B}$ is present at both the paranodal and the juxtaparanodal regions. In CGT-/- fibers, protein 4.1B is either diff used along the axon or found at the paranodes along with Caspr2. This summary is based on the present work, as well as on a previous work by Popko and colleagues (Dupree et al., 1999).

ization of membrane junctional components but also affects the distribution of downstream cytoskeletal elements such as protein 4.1. In the wild-type nerve, protein 4.1B was first detected with Caspr at the paranodes and only at a later stage with Caspr2 at the juxtaparanodal region. In contrast, in the absence of Caspr in CGT $-/-$ mice, protein 4.1B follows the distribution of Caspr2 and remains at the paranodes. These results suggest that protein 4.1B may be recruited to sites that contain Caspr and Caspr2, where it may assist in maintaining functional domains by linking these proteins to the axonal cytoskeleton.

Several mechanisms have been suggested previously to account for the mislocalization of Caspr in CGT-/- nerves, including the direct binding of Caspr to GalC and/or sulfatide, as well as misrouting of a yet unidentified glial ligand to the glial loops (Dupree et al., 1999; Popko, 2000). The latter is based on the proposed role of galactolipids in the formation of lipid rafts and the organization of the myelin membranes (Kramer et al., 1997; Kim and Pfeiffer, 1999; Simons et al., 2000). The finding that NF155 is reduced or absent from the paranodal loops of the galactolipids-deficient mice reported here raises the possibility that localization of the Caspr/contactin complex at the paranodal junction may depend on the presence of NF155 at this site. According to this model, it is likely that during development, the Caspr/contactin complex is recruited to axo-glial contact sites at the mesaxon and the paranodal loops by NF155. Nevertheless, the observation that NF155 is reduced in or absent from the paranodes of contactin null mice (Boyle et al., 2001) demonstrates that proper localization of all putative adhesion components of the paranodal junction is interdependent, rendering still feasible the possibility that other mechanisms may account for the paranodal defect observed in the galactolipids-deficient mice.

In summary, we have extended previous observations which demonstrated that Caspr2 forms a complex with $\mathrm{K}^{+}$channels at the juxtaparanodal region and have found that these molecules invariably appear together during development of peripheral nerves. The correct localization of this complex in myelinated axons depends on the formation of Caspr-containing structural barriers along the axon, whereas the disruption of these barriers in CGT and contactin null mice results in its mislocalization. Future analyses of Caspr2 null mice will reveal whether it is indeed essential for the proper localization of $\mathrm{K}^{+}$channels to the juxtaparanodal region.

\section{REFERENCES}

Arroyo EJ, Xu YT, Zhou L, Messing A, Peles E, Chiu SY, Scherer SS (1999) Myelinating Schwann cells determine the internodal localization of Kv1.1, Kv1.2, Kvbeta2, and Caspr. J Neurocytol 28:333-347.

Arroyo EJ, Xu YT, Poliak S, Watson M, Peles E, Scherer SS (2001) Internodal specializations of myelinated axons in the CNS. Tissue Cell Res 305:53-66.

Baumgartner, S, Littleton JT, Broadie, K, Bhat MA, Harbecke, R, Lengyel JA, Chiquet-Ehrismann, R, Prokop, A, Bellen HJ (1996) A Drosophila neurexin is required for septate junction and blood-nerve barrier formation and function. Cell 87:1059-1068.

Bekele-Arcuri Z, Matos MF, Manganas L, Strassle BW, Monaghan MM, Rhodes KJ, Trimmer JS (1996) Generation and characterization of subtype-specific monoclonal antibodies to $\mathrm{K}^{+}$channel alpha- and betasubunit polypeptides. Neuropharmacology 35:851-865.

Berglund EO, Murai KK, Fredette B, Sekerkova G, Marturano B, Weber L, Mugnaini E, Ranscht B (1999) Ataxia and abnormal cerebellar microorganization in mice with ablated contactin gene expression. Neuron 24:739-750.

Bhat AM, Rios JC, Lu Y, Garcia-Fresco GP, Ching W, St. Martin M, Li J, Einheber S, Chesler M, Rosenbluth J, Salzer JL, Bellen HJ (2001) Axon-glia interactions and domain organization of myelinated axons requires Neurexin IV/Caspr/Paranodin. Neuron 30:369-383.

Bosio A, Bussow H, Adam J, Stoffel W (1998) Galactosphingolipids and axono-glial interaction in myelin of the central nervous system. Cell Tissue Res 292:199-210.

Boyle MET, Berglund EO, Murai KK, Weber L, Peles E, Ranscht B (2001) Contactin orchestrates assembly of the septate-like junctions at the paranode in myelinated peripheral nerve. Neuron 30:385-397.

Coetzee T, Fujita N, Dupree J, Shi R, Blight A, Suzuki K, Popko B (1996) Myelination in the absence of galactocerebroside and sulfatide: normal structure with abnormal function and regional instability. Cell 86:209-219.

Davis JQ, Lambert S, Bennett V (1996) Molecular composition of the node of Ranvier: identification of ankyrin binding cell adhesion molecules neurofascin (mucin+/third FNIII domain-) and NrCAM at nodal axon segments. J Cell Biol 135:1355-1367.

Dupree JL, Coetzee T, Blight A, Suzuki K, Popko B (1998) Myelin galactolipids are essential for proper node of Ranvier formation in the CNS. J Neurosci 18:1642-1649.

Dupree JL, Girault JA, Popko B (1999) Axo-glial interactions regulate the localization of axonal paranodal proteins. J Cell Biol 147:1145-1152.

Einheber S, Zanazzi G, Ching W, Scherer S, Milner TA, Peles E, Salzer JL (1997) The axonal membrane protein Caspr, a homologue of neurexin IV, is a component of the septate-like paranodal junctions that assemble during myelination. J Cell Biol 139:1495-1506.

Huang JP, Tang CJ, Kou GH, Marchesi VT, Benz EJ, Tang TK (1993) Genomic structure of the locus encoding protein 4.1. Structural basis for complex combinational patterns of tissue-specific alternative RNA splicing. J Biol Chem 268:3758-3766.

Kim T, Pfeiffer SE (1999) Myelin glycosphingolipid/cholesterolenriched microdomains selectively sequester the non-compact myelin proteins CNP and MOG. J Neurocytol 28:281-293.

Kramer EM, Koch T, Niehaus A, Trotter J (1997) Oligodendrocytes direct glycosyl phosphatidylinositol-anchored proteins to the myelin sheath in glycosphingolipid-rich complexes. J Biol Chem 272:8937-8945.

Menegoz M, Gaspar P, Le Bert M, Galvez T, Burgaya F, Palfrey C, Ezan P, Arnos F, Girault JA (1997) Paranodin, a glycoprotein of neuronal paranodal membranes. Neuron 19:319-331.

Ohara R, Yamakawa H, Nakayama M, Ohara O (2000) Type II brain 4.1 (4.1B/KIAA0987), a member of the protein 4.1 family, is localized to neuronal paranodes. Brain Res Mol Brain Res 85:41-52.

Parra M, Gascard P, Walensky LD, Gimm JA, Blackshaw S, Chan N, Takakuwa Y, Berger T, Lee G, Chasis JA, Snyder SH, Mohandas N, Conboy JG (2000) Molecular and functional characterization of protein $4.1 \mathrm{~B}$, a novel member of the protein 4.1 family with high level, focal expression in brain. J Biol Chem 275:3247-3255.

Pedraza L, Huang JK, Colman DR (2001) Organizing principles of the axoglial apparatus. Neuron 30:335-344. 
Peles E, Salzer JL (2000) Functional domains in myelinated axons. Curr Opin Neurobiol 10:558-565.

Peles E, Nativ M, Lustig M, Grumet M, Schilling J, Martinez R, Plowman GD, Schlessinger J (1997) Identification of a novel contactinassociated transmembrane receptor with multiple domains implicated in protein-protein interactions. EMBO J 16:978-988.

Poliak S, Gollan L, Martinez R, Custer A, Einheber S, Salzer JL, Trimmer JS, Shrager P, Peles E (1999) Caspr2, a new member of the neurexin superfamily, is localized at the juxtaparanodes of myelinated axons and associates with K+ channels. Neuron 24:1037-1047.

Popko B (2000) Myelin galactolipids: mediators of axo-glial interactions? Glia 29:149-153.

Rasband MN, Shrager P (2000) Ion channel sequestration in central nervous system axons. J Physiol (Lond) 525:63-73.

Rasband MN, Trimmer JS (2001) Subunit composition and novel localization of K+ channels in spinal cord. J Comp Neurol 429:166-176.

Rasband MN, Peles E, Trimmer JS, Levinson SR, Lux SE, Shrager P (1999) Dependence of nodal sodium channel clustering on paranodal axoglial contact in the developing CNS. J Neurosci 19:7516-7528.

Rhodes KJ, Strassle BW, Monaghan MM, Bekele-Arcuri Z, Matos MF, Trimmer JS (1997) Association and colocalization of the $\operatorname{Kv} \beta 1$ and $\mathrm{Kv} \beta 2 \beta$-subunits with $\mathrm{Kv} 1 \alpha$-subunits in mammalian brain $\mathrm{K}^{+}$channel complexes. J Neurosci 17:8246-8258.

Rios JC, Melendez-Vasquez CV, Einheber S, Lustig M, Grumet M, Hemperly J, Peles E, Salzer JL (2000) Contactin-associated protein (Caspr) and contactin form a complex that is targeted to the paranodal junctions during myelination. J Neurosci 20:8354-8364.

Rosenbluth J (1995) Glial membranes and axoglial junctions. In: Neuroglia (Kettenmann H, Ransom BR, eds), pp 613-633. New York: Oxford UP.

Simons M, Kramer EM, Thiele C, Stoffel W, Trotter J (2000) Assembly of myelin by association of proteolipid protein with cholesterol- and galactosylceramide-rich membrane domains. J Cell Biol 151:143-154.
Tait S, Gunn-Moore F, Collinson JM, Huang J, Lubetzki C, Pedraza L, Sherman DL, Colman DR, Brophy PJ (2000) An oligodendrocyte cell adhesion molecule at the site of assembly of the paranodal axo-glial junction. J Cell Biol 150:657-666.

Vabnick I, Shrager P (1998) Ion channel redistribution and function during development of the myelinated axon. J Neurobiol 37:80-96.

Vabnick I, Trimmer JS, Schwarz TL, Levinson SR, Risal D, Shrager P (1999) Dynamic potassium channel distributions during axonal development prevent aberrant firing patterns. J Neurosci 19:747-758.

Walensky LD, Gascard P, Fields ME, Blackshaw S, Conboy JG, Mohandas N, Snyder SH (1998) The 13-kD FK506 binding protein, FKBP13, interacts with a novel homologue of the erythrocyte membrane cytoskeletal protein 4.1. J Cell Biol 141:143-153.

Walensky LD, Blackshaw S, Liao D, Watkins CC, Weier HU, Parra M Huganir RL, Conboy JG, Mohandas N, Snyder SH (1999) A novel neuron-enriched homolog of the erythrocyte membrane cytoskeletal protein 4.1. J Neurosci 19:6457-6467.

Wang H, Kunkel DD, Martin TM, Schwartzkroin PA, Tempel BL (1993) Heteromultimeric $\mathrm{K}+$ channels in terminal and juxtaparanodal regions of neurons. Nature 365:75-79.

Waxman SG, Ritchie JM (1993) Molecular dissection of the myelinated axon. Ann Neurol 33:121-136.

Winckler B, Forscher P, Mellman I (1999) A diffusion barrier maintains distribution of membrane proteins in polarized neurons. Nature 397:698-701.

Yamakawa H, Ohara R, Nakajima D, Nakayama M, Ohara O (1999) Molecular characterization of a new member of the protein 4.1 family (brain 4.1) in rat brain. Brain Res Mol Brain Res 70:197-209.

Zahraoui A, Louvard D, Galli T (2000) Tight junction, a platform for trafficking and signaling protein complexes. J Cell Biol 151:31-36.

Zimmermann H (1996) Accumulation of synaptic vesicle proteins and cytoskeletal specializations at the peripheral node of Ranvier. Microsc Res Tech 34:462-473. 